\title{
An Exploratory Insight on Pharmaceutical Sector and Pricing Policies in Qatar
}

\author{
Nada Abdel Rida ${ }^{1}$, Manal Zaidan², Mohamed Izham M Ibrahim ${ }^{1 *}$ \\ ${ }^{1}$ College of Pharmacy, Qatar University, Qatar \\ ${ }^{2}$ Aspetar, PO Box 29222, Doha, Qatar
}

Submission: February 09, 2017; Published: March 27, 2017

*Corresponding author: Mohamed Izham Mohamed Ibrahim, Clinical Pharmacy \& Practice Section, Qatar University, Qatar, Tel: 974555615789; Email: mohamedizham@qu.edu.qa

\section{Abstract}

Qatar is the world's highest per capita income non-OECD country as well as having the highest per capita health expenditure in the region. The Qatari pharmaceutical market reached a value of USD 559 million in 2016. There is a difference in pricing of dispensed medicines for Qataris and non-Qataris at the Hamad Medical Corporation health institutions. The development of the pharmaceutical market is shaped by the decision of the Ministry of Public Health (MoPH) formerly known as Supreme Council of Health (SCH) to abolish government controls over the pricing of medicines and to allow more importing agents and suppliers in the country and has resulted in the adoption of an open market system.

The retail prices of medicines remain among the highest in the region. There is no policy on the bioequivalence of generic medicines, but the government is promoting the use of generic medicines despite the extensive use of branded medicines in Qatar's healthcare facilities. A high share of imported and branded medicines, which are trusted and preferred by prescribers and consumers, has increased the Qatari government's healthcare spending. SCH's attempt to remove price controls had affected the affordability of medicines as the prices of some drugs had increased and were inconsistent across facilities. The government has had to implement price controls, although it abstained from explicitly fixing prices.

Keywords: Generic Medicines, Medicines, Medicines Policy, Pharmaceutical Sector, Pharmaceutical Pricing, Qatar

\section{Introduction}

Rising pharmaceutical expenditures have impacted healthcare systems across most countries worldwide. This phenomenon affects country's ability to provide affordable, equitable and good quality care to the society [1]. One of the most important strategies to overcome these challenges should be through the implementation of acceptable, comprehensive and feasible medicines policy.

Qatar desires to manage and develop an integrated healthcare system according to world-class standards in order to improve the health of Qatar's population. The plans are to improve the health and extend the life expectancy of its population and to meet the requirements of present and future generations. Overall healthcare services are intended to be accessible and affordable to the entire population. The healthcare system is available to all, regardless of nationality [2]. The population of Qatar is estimated to be 2.59 million in 2016, approximately $80 \%$ being expatriates [3]. In 2015, life expectancy at birth was 78 years [4,5]. Qatar is the world's highest per capita income non-OECD country. In 2014, GDP per capita (PPP) is estimated at USD 140, 649 vs USD 134, 117 in 2011 [6]. Health expenditure excluding the private sector accounted for 1.9\% of GDP in 2015 [7].

The Ministry of Public Health (MoPH), previously known as the Supreme Council of Health $(\mathrm{SCH})$, is responsible and committed to providing quality and effective healthcare services. It oversees the services delivered by public institutions such as Hamad Medical Corporation, Primary Health Care Corporation and the private sector to ensure compliance with standards and achievement of performance targets. It develops and regulates policies, and also oversees public health programs and environmental and public safety promotion [8].

The pharmaceutical sector is vital to supporting the achievement of high standard healthcare services. There is lack of information and comprehensive assessment of the pharmaceutical sector in Qatar especially in relation to medicine pricing policy. Health Action International (HAI) in collaboration with World Health Organization (WHO) have conducted studies in many countries on medicines prices but there is limited data on Qatar. It is appropriate to study the current status of the pharmaceutical sector before evaluating the price of medicines. 
Thus, this paper aims to assess the present pharmaceutical sector and its medicines pricing policy.

\section{Methodology}

A survey using secondary data was conducted to achieve the above study objective. Data was gathered from ministries, healthcare institutions, corporate and private organizations, international non-profit organizations and media. Materials used for gathering information and data are peer-reviewed articles, policy documents, national annual statistics, private sector and organization publications, daily newspaper and institutions websites. Information and data are analyzed descriptively as frequency and percentages, and presented in tabular form.

\section{Findings and discussion}

\section{Healthcare system}

Health service performance and diseases: Despite the increased life expectancy of the Qatari population, many people suffer from non-communicable diseases (NCDs) such as diabetes, cancer and heart disease. Qatar has committed to combat the widespread prevalence of NCDs and the morbidity associated with these diseases [9]. Table 1 demonstrates that the health services and personnel have improved over the years. There are 14 public, private and semi-public hospitals, 22 health centers, and 317 private, individual and multiple clinics. Hospital beds per 1,000 people have increased to 1.2 beds in 2014 . The total number of doctors has increased from 3.11 doctors per 1,000 people in 2006 to 4.03 in 2010 [9-11].

Table 1: Health service performance and diseases in Qatar during the period 1998-2012 [2,20,35].

\begin{tabular}{|c|c|c|c|c|c|}
\hline \multicolumn{7}{|c|}{ Year } \\
\hline Variables & $\mathbf{2 0 0 4}$ & $\mathbf{2 0 0 6}$ & $\mathbf{2 0 0 8}$ & $\mathbf{2 0 1 0}$ & $\mathbf{2 0 1 2}$ \\
\hline \multicolumn{5}{|c|}{ Total Number of Deaths } \\
\hline $\begin{array}{c}\text { Certain infectious and } \\
\text { parasitic diseases }\end{array}$ & 24 & 12 & 33 & 30 & 24 \\
\hline Neoplasms & 137 & 158 & 175 & 214 & 218 \\
\hline $\begin{array}{c}\text { Diseases of blood and } \\
\text { disorders of immune } \\
\text { mechanism }\end{array}$ & 5 & 7 & 10 & 10 & 9 \\
\hline $\begin{array}{c}\text { Endocrine, nutritional } \\
\text { and metabolic diseases }\end{array}$ & 93 & 114 & 101 & 125 & 134 \\
\hline $\begin{array}{c}\text { Diseases of the } \\
\text { circulatory system }\end{array}$ & 254 & 323 & 279 & 289 & 30 \\
\hline $\begin{array}{c}\text { Diseases of the } \\
\text { respiratory system }\end{array}$ & 80 & 62 & 65 & 76 & 74 \\
\hline $\begin{array}{c}\text { Congenital } \\
\text { malformations, } \\
\text { deformations and } \\
\text { abnormalities }\end{array}$ & 44 & 47 & 60 & 59 & 62 \\
\hline $\begin{array}{c}\text { External causes of } \\
\text { morbidity and mortality }\end{array}$ & 283 & 474 & 435 & 402 & 383 \\
\hline
\end{tabular}

\begin{tabular}{|c|c|c|c|c|c|}
\hline Transport accidents & 184 & 303 & 272 & 247 & 231 \\
\hline $\begin{array}{c}\text { Accidental poisoning by } \\
\text { and exposure to noxious } \\
\text { substances }\end{array}$ & 5 & 1 & 7 & 7 & 4 \\
\hline \multicolumn{7}{|c|}{ Year } \\
\hline Variables & 1998 & 2003 & 2008 & 2010 & 2012 \\
\hline
\end{tabular}

Incidence rates of selected infectious diseases/10000 [2, 20,35]:

\begin{tabular}{|c|c|c|c|c|c|}
\hline measles & 2.14 & 0.33 & 0.7 & na & na \\
\hline rubella & na & 0.68 & 0.48 & 0.85 & na \\
\hline meningococcal infection & 0.15 & 0.79 & 0.85 & na & na \\
\hline typhoid paratyphoid & 0.29 & 0.97 & 0.81 & na & na \\
\hline malaria & na & 4.88 & 1.28 & 1.49 & na \\
\hline viral hepatitis & 1.8 & 21.17 & 12.32 & na & na \\
\hline pulmonary tuberculosis & na & 2.56 & 2.18 & 2.11 & na \\
\hline chicken pox & 29.01 & 31.31 & 39.07 & na & na \\
\hline mumps & na & 1.99 & 1.33 & 2.04 & na \\
\hline shigellosis & 0 & 0.76 & 0.33 & na & na \\
\hline
\end{tabular}

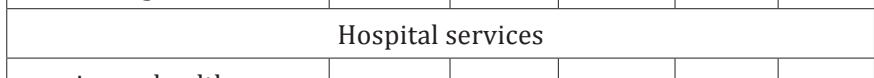

\begin{tabular}{|c|c|c|c|c|c|}
\hline $\begin{array}{l}\text { primary health care } \\
\text { centers (No.) }\end{array}$ & 32 & 30 & 30 & 30 & 30 \\
\hline population/center & 16979 & 24138 & 48282 & na & na \\
\hline hospitals (No.) & na & 3 & 10 & 12 & 14 \\
\hline beds (No.) & 1253 & 1468 & 2023 & 2218 & 2613 \\
\hline $\begin{array}{l}\text { beds per } 1000 \\
\text { population (No.) }\end{array}$ & na & 2.31 & 2.03 & 1.4 & 1.43 \\
\hline rate of bed occupancy & na & 78 & 75.5 & 81.3 & na \\
\hline average days of stay & 6.8 & 6.9 & 4.7 & 10.8 & 7.4 \\
\hline discharge daily average & na & 124 & 140 & 167 & na \\
\hline population/operation & 34.01 & 36.96 & 51.53 & na & na \\
\hline $\begin{array}{c}\text { population/daycare } \\
\text { surgery }\end{array}$ & 61.27 & 48.6 & 94.61 & na & na \\
\hline $\begin{array}{l}\text { percentage of hospital } \\
\text { deliveries }\end{array}$ & 98.24 & 98.44 & 98.34 & na & na \\
\hline $\begin{array}{c}\text { consultation length in } \\
\text { minutes per patient }\end{array}$ & $\begin{array}{c}5.8 \pm \\
2.4\end{array}$ & $\begin{array}{c}6.6 \pm \\
2.1\end{array}$ & $\begin{array}{c}6.9 \pm \\
2.5\end{array}$ & na & na \\
\hline \multicolumn{6}{|c|}{ Personnel } \\
\hline physicians (No.) & 968 & 1624 & 3259 & na & na \\
\hline physician/bed & 0.8 & 1.1 & 1.6 & na & na \\
\hline nurse/bed & 1.9 & 2.8 & 4.2 & na & na \\
\hline population/physician & 561 & 446 & 444 & na & na \\
\hline population/dentist & 3528 & 2577 & 1786 & na & na \\
\hline population/pharmacist & na & 1386 & 991 & 1099 & na \\
\hline population/nurse & 226 & 179 & 172 & na & na \\
\hline
\end{tabular}

Medical service facilities provider: HMC was established in 1982 and manages three general hospitals: Al Khor Hospital (149 beds), Al Wakra Hospital (350 beds) and the Cuban Hospital (75 beds); and five specialist hospitals: Hamad General Hospital (616 beds), Rumailah Hospital (362 beds), Women's Hospital (334 beds), the National Center for Cancer Care and Research (46 beds) and Heart Hospital (120 beds). HMC was awarded the 
Joint Commission International (JCI) certification for quality health facilities. In addition, under the Qatar Foundation, the country has now established Sidra Medical and Research Center, which focuses on patient care for women and children in Qatar.

Other than HMC, there are also a number of private medical facilities offering a full range of medical services, from specialist consultations, dentistry, home nursing care, rehabilitation, hospital procedures and surgeries.

Health expenditure: Qatar's total expenditure on health is $2.2 \%$ of GDP in 2014, with public spending allocated to health accounting for $1.9 \%$ of GDP $[5,12]$. In terms of healthcare expenditures, healthcare spending per capita in Qatar is the highest in the Middle East at 2,106 in 2014 according to the World Bank. There has been an enormous increase in public healthcare spending since 1991 reaching QR 1.3bn in 2003(Ministry of Health and HMC) [13]. In 2004, the spending increased by $28 \%$ to QR $1.67 \mathrm{bn}$. Overall, spending by HMC and National Health Authority (NHA) increased by circa $71 \%$ between 2000-2004. Of the QR 3.8bn healthcare budget for the 2006-2007 fiscal year, QR 239m was allocated to public works in the health sector [14].

National health insurance and coverage: A comprehensive overview of the Qatar national health insurance scheme was provided by Jones and Shlah [15]. The National Health Insurance Company (NHIC) is a fully owned government entity. The NHIC manages and operates the social health insurance scheme in Qatar. The scheme provides mandatory health insurance coverage through a network of public and private providers. The organization has also appointed a third-party administrator and subcontractors to manage the scheme. This scheme provided universal healthcare to members offering a choice of providers from both the public and private sectors. The scheme was launched in 2015, but was phased out in the first half of 2016 [16]. SCH has announced that a new system is being developed and will be implemented in 2016 [17].

\section{Pharmacy system}

Pharmacy authority: The Pharmacy and Drug Control Department (PDCD) manages, implements and regulates pharmaceutical policy, law and practice in the country. The subunits within PDCD are the drug registration section, drug release section, inspection and narcotic section, and quality control laboratory. The PDCD is accountable for recommending drug policy to the higher authority, registration of drug agents and importers, registration of drug companies and their products, and registration of herbal products, dietary supplements and medicated cosmetics. It controls narcotics and psychotropic drugs via import, storage and dispensing control and the quality of registered drugs, herbal products and dietary supplement via laboratory analysis. The PDCD is also engaged in the section of private (community) pharmacies, drugstores, herbal stores, and drug manufacturing companies to ensure that they are operating according to the pharmacy law and related regulations, and alternative working schedules.

Pharmacy practice in Qatar: The pharmacy practice in Qatar has rapidly advanced in recent years due to a number of national initiatives that have included accreditation programs of healthcare services, i.e. ,under JCI, opening the college of pharmacy, the first and only pharmacy college in the country, and a trend to employ those holding advanced degrees in pharmacy practice, e.g., the Pharm D. From a policy point of view, Qatar's National Health Strategy of 2011-2016 emphasizes diseases' management, health insurance and integration between both the government and private sectors. To improve efficiency and access and to decrease dependence on hospitals for filling prescriptions, the strategy also promotes a community pharmacy network supported by appropriate policy and processes [9].

Pharmacy workforce: The majority of pharmacy practitioners in Qatar are foreigners with degrees from Egypt, India, Sudan or Jordan [18]. The primary focus areas for these pharmacists are in private community pharmacies, public hospitals, primary healthcare settings and private clinics. (Table 2) [19]. The rate of pharmacists for every 1,000 people of the total population has shown a slight increase from 1.14 in 2006 to 1.17 in 2010 [2,9,20].

Table 2: Pharmacies and pharmacists' workforce in public and private sectors [19].

\begin{tabular}{|c|c|c|c|}
\hline $\begin{array}{c}\text { Type of } \\
\text { pharmacy }\end{array}$ & $\begin{array}{c}\text { Number of } \\
\text { pharmacies }\end{array}$ & $\begin{array}{c}\text { Number of } \\
\text { pharmacists }\end{array}$ & $\begin{array}{c}\text { Ratio } \\
\text { pharmacist/ } \\
\text { pharmacy }\end{array}$ \\
\hline Private & 173 & 538 & 3.11 \\
\hline PHCC & 21 & 171 & 8.14 \\
\hline HMC & 25 & 255 & 10.2 \\
\hline Other & 8 & 34 & 4.25 \\
\hline Total & 227 & 998 & 4.4 \\
\hline
\end{tabular}

Pharmacy practice regulations: There is no independent professional pharmacy association that controls the pharmaceutical practice and represents or promotes the profession of pharmacy in Qatar. These roles fall under the prerogative of the $\mathrm{SCH}$, and a Pharmacy Law provides the legal framework that governs the practice. The pharmacy laws cover prescription medicine, pharmacists' registration and practice in Qatar, and pharmacy ownership.

\section{Qatar Pharmaceutical Profile}

Pharmaceutical supply: Drug procurement, storage, and supply follow organized and well-established protocols. The rules and regulations governing these inventory-related activities are generally similar to those in other neighboring Middle Eastern countries; and several Gulf countries (members of the GCC) purchase their annual quota of medicines through a joint procurement process. This process imposes the political commitment of their member states. The country ensures a cost-effective procurement process through the adoption of 
a centralized tendering system. In a study conducted in Qatar, practicing pharmacists felt that the regulatory procedures for the procurement, storage, marketing, and pricing of medications are acceptable and they appeared to be satisfied with the processes associated with dispensing medications in retail settings, public clinics, and public hospital outpatient pharmacies [21,22].

Imported medicines account for $97 \%$ of the pharmaceutical market [17]. Public sector drug procurement is carried out through closed international tenders, GCC bulk procurement and direct purchasing. If the amount is less than QR 500, 000, procurement is through direct purchase; if more than QR 500, 000, it is through tender. Emergency supplies are provided directly from local pharmaceutical distributors to government hospitals. There is a special non-restricted procedure of procuring medicines for the Qataris. As mentioned, PDCD ensures that imported medicines are of good quality, safe and effective. Not all medicines registered in PDCD are available in HMC and vice versa.

According to PDCD, there are approximately 4,599 registered pharmaceutical products in Qatar (final list updated on April, 2016) that are supplied and distributed by 19 registered companies; Ebn Sina Medical Company is the largest suppliers. In addition, Sidra Medical and Research Center's Procurement and Contracts (P\&C) Department manages the sourcing of its goods and services either through HMC bulk procurement or through direct interaction with pharmaceutical suppliers. Medicines dispensed at the HMC health institutions are charged differently. For nationals (and exempted individuals such as GCC, if the mother is Qatari), medicines are free of charge and are now covered by the new insurance system. Non-nationals who are residents have to pay $20 \%$ of the HMC prices. Medicines in the public sector, i.e., hospitals, are selected through the pharmacy \& therapeutic committee. HMC hospitals have their own hospitalbased formulary [21]. In December 2015, SCH launched the Qatari formulary website [23].

Pharmaceutical market: Qatar imported an estimated USD 428.2mn worth of pharmaceutical products in 2015, compared to USD $18.2 \mathrm{mn}$ in pharmaceutical exports [24]. In 2009, Qatar Pharma began production and was presumably the only local pharmaceutical manufacturing company that operates on a reasonable scale. However, domestic drug production is gradually gaining momentum in the country. Other pharmaceutical companies under establishment are Qatar Al-Hayat, Q-Med; Al-Mutamayyiz Factory for pharmaceutical products, Doha Factory for pharmaceutical products, and a factory for medical solutions and intravenous nutrients (all 5 have been granted for initial approval). This move is aimed to reduce dependence on imported medicines.

The Qatari government favors increasing local production. SCH stipulates all doctors to prescribe medicines only by their generic names in order to promote expansion of generic drugs in the market, hence leaving the final choice of generic or branded drugs to the patients. However, it remains to be seen whether generic drugs are able to penetrate the country with the rich and brand conscious consumer base. The pharmaceutical industry in the GCC is projected to undergo sustainable growth in the medium to long term. Increased production domestically, coupled with foreign investment and consumption of generics are expected to support the market's evolution. The growing number of lifestyle-related chronic diseases has increased demand for high-value prescription medication in Qatar. People are also becoming increasingly aware of personal healthcare, which has boosted sales of OTC products such as cold and flu medication, analgesics, digestives, and topical creams. However, regulations on advertising and retail sales through licensed pharmacies have only partially stunted the growth of the OTC segment. Under Qatari laws, some OTC drugs are categorized as prescription medicines, while some drugs generally available under prescription-only are dispensed OTC $[25,26]$.

The Qatari pharmaceutical market reached a value of QAR2.04 billion riyals (USD559 million) in 2016, valued at USD524million in 2015 and with $6.8 \%$ growth. It is forecasted to growth with a compound annual growth rate of $6.4 \%$ between 2015 and 2020 to reach QAR2.60 billion (USD 714mn). Under the present system, registered importers are responsible for medicines' quality and they are required to produce documentation showing that the drugs conform to international standards and are approved for sale in neighboring countries such as United Arab Emirates (UAE), Saudi Arabia and Kuwait. Opening up the market to more companies will create an enormous challenge in terms of monitoring for quality [17].

\section{Medicine Expenditure and Prices}

Qatar's public sector expenditure in 2014 was USD3,940 million, almost double the USD 2,028 million in 2010[17]. The issue of medicine pricing is under the jurisdiction of MoPH. The Pharmacy and Drug Control Department in conjunction with other stakeholders recommend prices for medicines which are then approved by the Ministry of Finance. Qatar has implemented a free market system. To bring down prices of medicines and to ensure a continuous supply, all registered and licensed importers as well as dealers in drug importations have been allowed to fix retail prices of the medicines against the initial price control mechanisms of the council.

Historically, drug prices are determined by the Pharmacy and Medical Control Department, Qatar Ministry of Health under the Law No. (7) of 1990. The medicine pricing considerations are based on the following aspects: original value for medicines; value of insurance for the medicines; wages of freight to the port in Qatar; value of custom fee; and expenses of unloading, excluding the demurrage. The pricing process included 15\% profit margin to importers and nearly $25 \%$ margin to retailers. The retailers received stocks from wholesalers with the prices printed on each pack of medicines. Retail outlets were bound 
to keep the printed prices. The foreign currency exchange rate was fixed. Under the initial registration law of 1986, by Pharmacy and Medical Control Department, SCH, products have to be registered with the PDCD at the SCH. These old law and procedures have caused few problems. The Qatari market faced a shortage of certain drugs and high drug prices, which were said to be among the highest in the region.

The development of Qatar's pharmaceutical market was shaped by the decision made by the SCH to abolish government controls over the pricing of medicines and to allow more importing agents in the country. Prior to this new initiative, there was a small number of importing agents that had caused high pharmaceutical prices. In April 2011, the Law No. (7) Of 1990 by the Pharmacy and Medical Control Department was reviewed and repealed. As part of Qatar's public health strategy for 2011-2016, and based on complaints by consumers about high prices and non-availability of some drugs, a new law was enacted. Free pricing has provided a way for medicine supply chain companies to increase their margins and counter foreignexchange fluctuations.

The market saw an unprecedented increase in medicine prices even though it was anticipated that the elimination of a medicine price ceiling would help decrease drug prices. However, according to anecdotal reports from the Peninsula, Gulf Time and Pharma Times, consumers were surprised to find that wholesalers had increased product prices by as much as $30 \%$ within days of the ending of government controls [2730]. Furthermore, Gulf News reported the difference in medicine prices (Table 3) before and after the introduction of the new law [31]. The cabinet has approved legislation suggested by the SCH that seeks to boost competition in the market by ending the monopoly held by the 19 suppliers/distributors currently licensed to bring medicines into the country. It is believed that these market liberalization measures will again reduce drug prices.

The regulations previously made the retailers stock only the most expensive drugs in order to maximize their profit margins. The new system provides an opportunity for lower-priced branded drugs and generics to move into Qatar's pharmaceutical market. Nevertheless, the market's value at consumer prices will result from both upward (including healthcare modernization and high per capita GDP) and downward pressures. The main downward pressure is the fact that open market competition on drug prices, and the availability of cheaper alternative drugs, should drive down artificially inflated prices. SCH has stated that drug manufacturers will still need to obtain import licenses by meeting stringent regulatory conditions.

When prices were fixed, many retailers complained of thin margins which were supposedly not sufficient to compensate for overhead costs. Retail prices of medicines in Qatar remain among the highest in the region despite the abolition of the drug pricing law by the PDCD in April 2011 and several attempts to harmonize the prices regionally. By the end of 2014, the GCC enacted the pharmaceutical price harmonization which resulted in an ongoing gradual decrease of pharmaceutical prices from end of 2014 till present (2016) [17,32]. The higher regional prices are mostly due to the higher markup rates compared to other GCC countries such as Saudi Arabia [28]. The move had aimed to bring down the retail prices of OTC medicines in local pharmacies across the country. The officials also mentioned that plans to establish four new pharmaceutical companies in the country would help reduce drug prices [33]. During mid till late 2014, the government reviewed its policy again, set and controlled prices of around 350 medicines with the aim of unifying prices of medicines across the country. The new rates were reportedly intended to standardize drug prices across the GCC [34]. This strategy has been implemented and resulted in lower prices in the Qatari market by dividing the medicine classes into groups starting with the chronic disease medicine classes (Table 3).

Table 3: Selected products with price increase in Qatar.

\begin{tabular}{|c|c|c|c|c|c|}
\hline & $\begin{array}{c}\text { Previous } \\
\text { Price } \\
\text { (QR) }\end{array}$ & $\begin{array}{c}\text { Post } \\
\text { April } \\
\mathbf{2 0 1 1} \\
\text { Price } \\
\text { (QR) }\end{array}$ & $\begin{array}{c}\text { \% } \\
\text { Change }\end{array}$ & $\begin{array}{c}\text { Price } \\
\mathbf{2 0 1 6}\end{array}$ & $\begin{array}{c}\text { \% } \\
\text { Change } \\
\text { (2011- } \\
\text { 16) }\end{array}$ \\
\hline $\begin{array}{c}\text { Lipitor } \\
\text { (atorvastatin; } \\
\text { 10 mg) }\end{array}$ & 163.75 & 219 & 33.7 & 140.25 & $-36 \%$ \\
\hline $\begin{array}{c}\text { Norvasc } \\
\text { (amlodipine; } \\
5 \text { mg) }\end{array}$ & 85.5 & 92 & 7.6 & 69.5 & $-25 \%$ \\
\hline $\begin{array}{c}\text { Januvia } \\
\text { (sitagliptin; } \\
\text { 100 mg) }\end{array}$ & 323.75 & 400 & 24 & 157 & $-60.10 \%$ \\
\hline
\end{tabular}

\section{Generic Medicines Policy}

The government tends to purchase branded products; however, the share of the generic drug market is increasing [17]. There is no policy on generic medicines bioequivalent, but the government is promoting the use of generic medicines. HMC is using brands mainly because of prescribers' preference, patient trust and unavailability of a bioequivalence center in Qatar. There are no criteria to select generics such as the FDA orange book.

This is contributing to additional healthcare costs that could have been avoided. Under the National Health Strategy 20112016 (Project 5.4) [26], the government has focus on generic medicines use awareness in the country. SCH has proposed several behavioral and utilization studies to assess issues regarding generic medicines among public and healthcare providers, i.e., levels of utilization, perception, knowledge, and practice. In 2015, the generics sales constituted approximately $30 \%$ of the patented drug sales in the country (QAR 0.400 and $1.303 \mathrm{bn}$ respectively). The 2020 forecasted sales are expected to stay in the same ratio for both drug types. $21.8 \%$ of drug sold 


\section{Global Journal of Pharmacy \& Pharmaceutical Sciences}

will be generics while the patented will form $69.5 \%$ of the total sale by the end of this decade [24]. Prescription drugs continued to dominate the market, accounting for close to $90 \%$ of sales by value [17].

In Arab States, the World Bank report warns of the impact of poverty and the huge disparity in wealth in the Middle East. Rich and wealthy Arabs are needed to undertake a related approach at the very least through investing their wealth in productive projects, e.g., pharmaceutical companies for generic medicines in Arab countries or in countries and regions of the marginalized and poor. That way, Arabs can bridge the gap between people lacking basic needs, e.g., essential medicines and life requirements rather than relying on imports of branded medicines from abroad forever, which is the case in all Arab countries, especially the six GCC states. The multinational pharmaceutical companies have been successful in the Qatari market due to people's high brand consciousness for both prescription and OTC (over-thecounter) medicines. There is low interest among multinational manufacturers to set up manufacturing plants in the country due to the small market size. Instead, the country prefers to import medicines primarily from USA, UK or other European countries and others from the MENA and Asian countries.

\section{Conclusion}

A high share of imported and branded medicines, caused by prescriber and consumer trust and preference, has inflated healthcare spending of the Qatari government, the main buyer of medicines, and consumers. A small market size and high income per capita has affected government's strategy to curb high medicine prices in the country. Previously, SCH's attempt to remove price controls had affected the affordability of medicines as the prices of some drugs increased. The recent change has caused the government to reintroduce price controls, although prices especially in the private sector are still considered unaffordable for the lowest-income strata.

\section{Funding}

This research received no specific grant from any funding agency in the public, commercial, or not-for-profit sectors

\section{Acknowledgment}

The authors would like to acknowledge Springer International Publishing Switzerland 2015, in Z.U.D. Babar (ed.), Pharmaceutical Prices in the 21st Century.

\section{Declaration of Conflict of Interest}

The Author(s) declare(s) that there is no conflict of interest.

\section{References}

1. Majid D, Tom W, Alan H (2011) Pharmaceutical policy and market in Iran: past experiences and future challenges. Journal of Pharmaceutical Health Services Research 2(1): 47-52.

2. Hamad Medical Corporation 2016 (19-06-2016)

3. MDPS. Monthly figures on total population: Ministry of development planning and statistics; 2016 (20-07-2016).

4. Data, life expectancy at birth: The World Bank Group; 2016 (20-072016).

5. UNICEF. Statistics 2014 (23-02-2014).

6. Data, GDP per capita, PPP (current international \$): The World Bank Group; 2016 (20-07-2016).

7. Data, Health expenditure, public (\% of GDP): The World Bank Group; 2016 (20-07-2016).

8. Ministry of Foreign Affairs, Qatar 2016 (20-06-2016).

9. SCH. Qatar healthcare facilities master plan 2013-2033 Doha, State of Qatar2014 (20-07-2016).

10. Primary Health Care Corporation 2014 (20-07-2016).

11. Data, hospital beds (per 1,000 people): The World Bank Group; 2016 (20-07-2016)

12. Data, health expenditure, total (\% of GDP): The World Bank Group; 2016 (20-07-2016).

13. Data, Health expenditure per capita (current US\$): The World Bank Group; 2016 (20-07-2016).

14. EMRO. Health system profile Qatar: WHO, EMRO; 2006 (20-07-2016).

15. Wayne J, Ramiz S (2013) Qatar national health insurance scheme update: executive regulations: Clyde \& Co (cited 10-04-2014).

16. Shabina SK (2015) Qatar's health insurance program Seha is being suspended. Doha News.

17. Qatar Pharmaceuticals \& Healthcare Report - Q2 2016: BMI research; 2016 (28-03-2016)

18. Kheir N, Zaidan M, Younes H, El H M, Wilbur K, et al. (2008) Pharmacy education and practice in 13 Middle Eastern countries. American journal of pharmaceutical education 72(6): 133.

19. Kheir N (2016) Pharmacy practice in developing countries.. Chapter 7. In: Ahmed F, Ibrahim M, (eds), Achievements and challenges, Academic Press, Massachusetts pp 516.

20. SCH (2014) Qatar Health Report 2012 Doha, Qatar2014 (05-06-2016)

21. Kheir N, Fahey M (2011) Pharmacy practice in Qatar: challenges and opportunities. South Med Rev 4(2): 92-96.

22. Maguy SEH, Nadir K, Manal Z, Peter JJ (2011) Pharmacist characteristics, medication use perceptions, and professional satisfaction: a first national survey in the state of Qatar. Journal of Healthcare Leadership 3: 9-28.

23. Qatar National Formulary (QNF) Doha (2015)Qatar: Supreme Council of Health.

24. Qatar Pharmaceuticals \& Healthcare Report - Q2 (2016) BMI research.

25. Awaisu A, Kheir N, Ibrahim MI, Hajj E-M, Hazi H, et al.(2014) Knowledge, attitudes, and practices of community pharmacists on generic medicines in Qatar. Int J Clin Pharm 36(2): 394-404.

26. National health Strategy 2011-2016 2014 (16-12-2015)

27. SCH (2011) price cap hurting pharmacies: Traders. The Peninsula.

28. New law aims to cut drug prices (2011). Gulf Times. 2011-04-20.

29. Lynne T (2010) Qatar is to abolish drug price fixing. PharmaTimes Media Limited.

30. Lynne T (2011) Qatar drug prices soar after law change. PharmaTimes Media Limited.

31. Pharmacies sell same medicine at different prices (2013) GulfTimes. 
32. Patricia LDG (2014) GCC Price Harmonization Process Implications And Outcomes. Outsourced Pharma.

33. Medicine prices set to drop in Qatar (2014) GulfTimes.

34. Peter K (2014) Drug prices set to drop in Qatar. Doha News.
35. Bener A, Mazroei AA (2010) Health services management in Qatar. Croat Med J 51(1): 85-88.

This work is licensed under Creative

Commons Attribution 4.0 License

DOI: 10.19080/GJPPS.2017.01.555568

Your next submission with Juniper Publishers
will reach you the below assets
- Quality Editorial service
- Swift Peer Review
- Reprints availability
- E-prints Service
- Manuscript Podcast for convenient understanding
- Global attainment for your research
- Manuscript accessibility in different formats
( Pdf, E-pub, Full Text, Audio)
- Unceasing customer service
Track the below URL for one-step submission
https://juniperpublishers.com/online-submission.php

